\title{
Knowledge Management Assessment Using PDCA based in Global and Local Standards: in the Case of Technics and I nformatics Studies
}

\author{
Vesna S. Ružičicíi ${ }^{*}$ and Živadin M. Micić ${ }^{2}$ \\ ${ }^{1,2}$ Faculty of Technical Sciences in Čačak, University of Kragujevac, Serbia \\ Svetog Save, 65, 32000 Čačak - Serbia \\ 1] [e-mail: vesna.ruzicic@ftn.kg.ac.rs] \\ 2[e-mail: micic@kg.ac.rs] \\ *Corresponding author: Vesna S. Ružičić
}

Received January 10, 2018; revised April 24, 2018; revised August 23, 2019; accepted February 12, 2020; published May 31, 2020

\begin{abstract}
This research aims to contribute to the discipline of knowledge management (KM) in Higher Education (HE), and is conducted using the case of the study programme (SP) for Integrated Academic Studies (IAS) of Technics and Informatics (TI). A deduction-induction methodology is applied, using a Plan-Do-Check-Act (PDCA) approach to design a suitable KM concept for making improvements to the SP IAS TI on the standardisation platform. Based on the application of the International Classification of Standards (ICS), the research analyses the correlations and competences acquired during the courses within the accredited TI study programme of two-course studies. On the basis of the results of a comparative analysis of the developmental learning process and educational goals, it is shown that knowledge management in correlation with standardisation leads to the improvement of study programmes in the upcoming accreditation cycle on the standardisation platform. Frequent innovations within standardised thematic fields (daily, weekly, monthly, etc.) indicate the need for appropriate changes to the SP. The contribution to KM is through an original analysis of annual samples of more than 90,000 standardised sources in correlation with the TI study programme. Expert System (ES) modelling and the original results enable an analogous contribution to the future KM of other SPs.
\end{abstract}

Keywords: Innovation, Knowledge Management, Technics and Informatics (TI), Standardisation, ISO, SRPS

Acknowledgements of research support along with grant numbers: The work presented here was supported by the Ministry of Education and Science of the Republic of Serbia (Project III 44006, http://www.mi.sanu.ac.rs/projects/projects.htm\#interdisciplinary). 


\section{Introduction}

$\mathbf{O}_{\text {ne of the objectives of higher education (HE) is the transfer of scientific and professional }}$ knowledge and skills [1]. This can be achieved only if the study programmes follow international (ISO) [2] and national (SRPS) [3] standards. This research on the study programme (SP) for integrated academic studies (IAS) of technics and informatics (TI, 50 subjects according to [4] - the SP was accredited in 2009 for the enrolment of 40 students, and in 2014 for 30 students, Guide for Students [5], page 33/91) is based on the current international classification of standards (ICS). In every business operation, it is necessary to follow and apply international/global (ISO) [2] and national/ local (SRPS) [3] standards in fields with a high level of innovation such as Information Technology (IT) [6], as well as in all other standardisation fields. Some of the key terms, which are standardised in the respective dictionaries (for example, [7], etc.), are written in italics. Possibilities for knowledge management (KM) [8] on the basis of expected competence (outcome and knowledge) are different in standardised fields. The improvement of the study programme quality, as well as of business processes, is achieved on the basis of competence (outcome and knowledge) which is the function of KM. This research is carried out according to the PDCA approach, using deduction for knowledge modelling from a course within two segments of TI on the example of SP TI (hypothesis 1), and induction for the expected target contributions - knowledge management (hypothesis 2).

The starting point for knowledge management on the standardisation platform are: knowledge sources (KS), trends in innovativeness, and knowledge innovation in fields with a high level of innovation within the study of technics and informatics. The possibilities for innovation monitoring, resource planning and solving of specific tasks and problems depend on the formation of a knowledge base (KB) [7]. To improve the quality of technics and informatics studies requires the application of a model which is as realistic as possible, including a target model of excellence in PDCA (Plan-Do-Check-Act) [9]. Integration into the world of information and education is conditioned by the necessity of KM and adjustment to world-class teaching processes, standards and norms at the level of quality assurance approaches (QAA) and quality management approaches (QMA). Initial standardisation in the field of Manufacturing Engineering (ICS1 = 25) in higher education - which includes a number of courses in technics studies and the IT field (ICS1 $=35$ ) with numerous courses on informatics studies - requires the target level of QAA for knowledge modelling, KB and software development of an Expert System (ES) for KM.

On the basis of the conducted research, the possibilities for KM are analysed on the basis of KS correlations in ICS fields, and competences acquired during the courses within one accredited SP of two-course studies (TI).

\subsection{Problem of Knowledge Innovation}

Innovation of knowledge sources in standardised fields (ICS1 = 01 to 99) can be regarded on a daily, weekly, monthly or an annual basis, while there can also be periods without any innovations. Experts in domain knowledge (DK) have a significant role in innovation monitoring in DK [10]. In the fields with the highest intensity of knowledge innovativeness, the following problems should be systemically solved: innovation monitoring, knowledge innovativeness, KB, knowledge systems base (KBS) and the development of KM software. On the standardisation platform, this requires time: consistent daily, weekly, monthly or yearly acquisition of knowledge or skills (ISO/IEC 2382-36, learning - 36.01.01) [11]. The fields 
with the highest intensity of innovation are the focus of this research, i.e. two segments: technics with a number of standardised fields of high (daily) innovativeness, and informatics/ IT with numerous subfields/courses. The problem is the possibility of innovation monitoring in all the fields/subfields/courses of the SP IAS of technics and informatics (daily, weekly, etc.).

The key problem is the possibility of knowledge innovation in all the courses of SP TI, which would ensure that the study programmes follow the international ISO and national SRPS standards.

\subsection{The Research Goals and Initial Hypotheses}

The purpose or goals of the paper can be presented at several levels:

- knowledge management (KM) at the highest level (level of the state architecture of knowledge),

- improvement of higher education (SP - using the example of the SP IAS TI), at the middle levels (level of institution, university, departments, at the same time in correlation with ICS),

- improvement of the competencies (of both teachers and students) at the operational levels of products/ processes/ systems (corresponding education/ in PDCA/ IES), using the example of relevant courses.

The research examines KM on the standardisation platform on the basis of knowledge source correlations in the standardised fields, using the example of the SP IAS TI. The main goal of the research is to contribute to knowledge management in higher education, through the example of the SP IAS TI. KM modelling is conducted by the introduction of correlations based on the analysis of the results from two aspects: 1) standardisation, and 2) competence (outcomes and knowledge) of graduate students/users.

Starting from KS, innovativeness in the observed domain knowledge is determined on the basis of comparative indices, the quantity index (Iq) and value index (Iv). The research is aimed at knowledge modelling for the advancement of study programmes, and at the development of KBS and KM software, as well as at the application of international (ISO) and national (SRPS) standards in ICS fields.

The initial hypotheses are summarised and examined below in terms of the PDCA approach, using the methods of deduction $\left(\mathrm{H}_{1}\right)$ and induction $\left(\mathrm{H}_{2}\right)$ :

$\mathrm{H}_{1}$ (Plan - Do - There is a possibility for KM on the basis of the correlations between the SP and international (ISO) and national (SRPS) standards. This means that there is a need for knowledge modelling and $\mathrm{KM}$ with the aim of continuous innovation monitoring in the standardised fields of SP TI;

$\mathrm{H}_{2}$ (Check - Act) - KM enables knowledge modelling, checks and monitoring of the standards in the fields of high innovativeness through software development and implementation. This represents an advancement in terms of KM for study programmes and the results of higher education.

In order to prove the above-mentioned hypotheses, using the example of the SP IAS TI, this research into standardisation and an analysis of survey data were conducted and presented (e.g. SP IAS TI). The ultimate goal of the research is the development of appropriate KM software, as well as team work enhancement, monitoring of knowledge innovation in all fields (both on global and local standardisation platforms) and the advancement of future studies and business processes. 
On the basis of the initial hypotheses and research goals, knowledge modelling (H1) is conducted in order to arrive at the project solutions (H2) for the development and implementation of an information-expert system (IES). To this end, the subsequent sections present the following: relevant papers on KM from the aspect of standardisation (Section 2.1), the example of the SP (Section 2.2), a comparison with previous studies (Section 2.3), the methodology used in this study (Section 3), concrete results and analysis in separate standardised fields (Section 4.1), and from the aspect of the survey results (Section 4.2). Subsequently, on the basis of the research results, there follows a discussion of the potential contribution of $\mathrm{KM}$ in correlation with standardised fields, for the courses in TI studies (Section 5.1). Then, in correlation with KBS, innovation through software development is proposed in accordance with the proposed hypothesis (Section 5.2). Finally, Section 6 points to further conclusions which may be drawn and directions for further research are proposed, again following the dual PDCA methodology (deduction and induction).

\section{Related Work}

Previous research related to KM is analysed from two aspects - studies of global and local standardisation frameworks (Section 2.1), and the examples of study programmes (Section 2.2). Section 2.3 presents a comparison of the previous research with this study.

\subsection{Knowledge Management from the Aspect of Global (ISO) and Local (SRPS) Standardisation}

Viewed in terms of standardisation and leadership [12], as in the present study, international (ISO) and national (SRPS) standards in the process of education introduce changes into management frameworks and future business processes [13]. The PDCA methodology has proved to be a good way for implementing KM and quality improvement in different work fields, for example, in the fields of quality [14] and IT [15], as well as in modelling the process of education on the basis of international (ISO) and national (SRPS) standardisation [16]. A model based on knowledge [17] for continuous monitoring of innovativeness [18] in educational processes often gives a more realistic picture at the local (SRPS) level, where knowledge represents the main criterion for competitiveness [19] in future business process.

The paper [20] presents the systematisation of 70 references (on the standardisation platform) for software and system development in PDCA, before and after 2010 (in PDCA $_{\text {2010-before [39-71] and in PDCA }}$ 2010-after [72-108]).

The PDCA (methodology ([2], ISO/IEC 20000-1:2011), model ([2], ISO/IEC 12207:2017, ISO/IEC 27001:2013, [3], SRPS ISO/IEC TR 15271:2007), cycle (or Deming cycle, ISO 9001:2015 and SRPS ISO 9001:2015) and concept (or quality loop, ISO 8402:1994) or quality spiral is a similar concept) has been proved to be satisfactory ...

\subsection{Knowledge Management: Examples from Study Programmes}

Acquisition of both knowledge and skills and KM within study programmes require the analysis of students' knowledge to be built into the educational process, as in the case of users in a business process. Knowledge management in teaching is based on some important aspects of study programmes, such as knowledge exchange from appropriate literature [21], the use of the Internet in different domains of knowledge [22] and the creation of models for the support and analysis of economic feasibility [23]. Knowledge management in teaching based on standards [24] contributes to the enhancement of global educational policy, study programmes subject to the process of accreditation [25], and education of teachers/master professors (TI). 
Based on the frequency of innovation monitoring on the example of TI master professors, the monitoring of innovations was found to be unsatisfactory [26]. Knowledge management within study programmes must take account of the organisational structure [27], methods for identifying KM activities [28], and the use of software for an effective teaching process of technical education [29]. Availability and accessibility of KS [18] enables a more stable basis for the implementation of activities in terms of knowledge modelling and more effective knowledge management [30].

\subsection{Comparison of Previous Work with this Study}

In contrast to the clustering applied by other authors, as in [31], the clustering principle applied in this paper is similar to that in [32]. While only one field has been clustered in [32] - on the second level of knowledge source (ICS2 = 29, Electrical Engineering), in this paper, the research has covered all the fields (ICS1 = 01 to 99). Research in other papers has also been focused on only one ICS field [33-35]. The paper [36] written by the same authors presents some elements of the research in all ICS fields. However, there are some shortcomings: the paper only provides the samples from one year of research, without surveys and with no access to KM and other correlations with the results of contributions to the improvement of one study programme. Other study programmes could be analysed based on these results [5].

Many studies have been carried out on the subject of "Knowledge management in higher education" (some aspects of KB [37] or Knowledge Modelling [38], etc.). However, the authors of this manuscript have based the research on the quality of SP on the ICS platform. This presents the main difference of this paper from other papers. In conclusion, the barriers that all authors dealing with this topic encounter relate to the fact that they are not able to follow the rapidity of innovation in IT standardisation [39]. The examples are numerous:

- the value of innovations per year (for ICS1 $=35$, in the form of standardised knowledge sources) amounts to 50,000.00 euros, which presents a barrier to many authors (as individuals). The solution to this problem may be found in the national knowledge architecture, [39], with appropriate accompanying software,

- the standardisation of the software development and lifecycle [40] is accompanied by the need for a series of ISO 25000 standards, as well as a supporting methodology in IT which is in correlation with other methodologies,

- 653 knowledge sources have been published in the form of standards within only one year (2017) in only one field (IT), (of these 319 were ISO/IEC standards with a value of 41,622 CHF and 334 were SRPS standards with a value of 12,364 CHF, CHF is the currency of Switzerland, $1 \mathrm{CHF} \approx 0.85 €$ ) [39].

\section{Methodology and Study Framework}

The results are analysed within two research frameworks: the first framework refers to the standardised fields of the SP TI, and the second refers to the survey research. Two segments of the SP TI are in focus: a segment on technics with several standardised fields of high (daily) innovation, and a segment on informatics, i.e. a field of Information Technology (IT) with numerous subfields/courses.

\subsection{Methodology}

The methodology used in this paper consists of a web search, statistical analysis, multi-criteria analysis, clustering, deductive and inductive methods. The data has been collected from the 
website of the International Organisation for Standardisation [2] and the National Institute for Standardisation [3]. Data selection has been conducted in terms of clustering [31] and determining the index of innovativeness. A sample of more than 90,000 standardised knowledge sources of several statistical time series was observed. The survey research was conducted in the form of a questionnaire filled in by the students of the Faculty of Technical Sciences in Čačak, University of Kragujevac. Knowledge modelling with the students who attend courses within the technics and informatics SP was carried out using the deduction method, while KM was realised using the induction method and PDCA approach.

The research methodology involves the advancement of KM on the standardisation platform, with a focus on two segments: technics, including standardised fields of high (daily) innovativeness, and informatics, i.e. the field of Information Technology (IT) which includes numerous subfields/courses.

The questionnaire covers 12 aspects of IT. The survey sample consists of students in the third, fourth and fifth years of the SP IAS TI [4] and students who had completed these studies.

The PDCA methodology has been applied in this paper, as well as in the papers [14], [17] and [20], Fig. 1. This paper provides the specific aspects of the methodology of modelling, development and updating of $\mathrm{KB}$, for the needs of the end user in the form of software - IES.

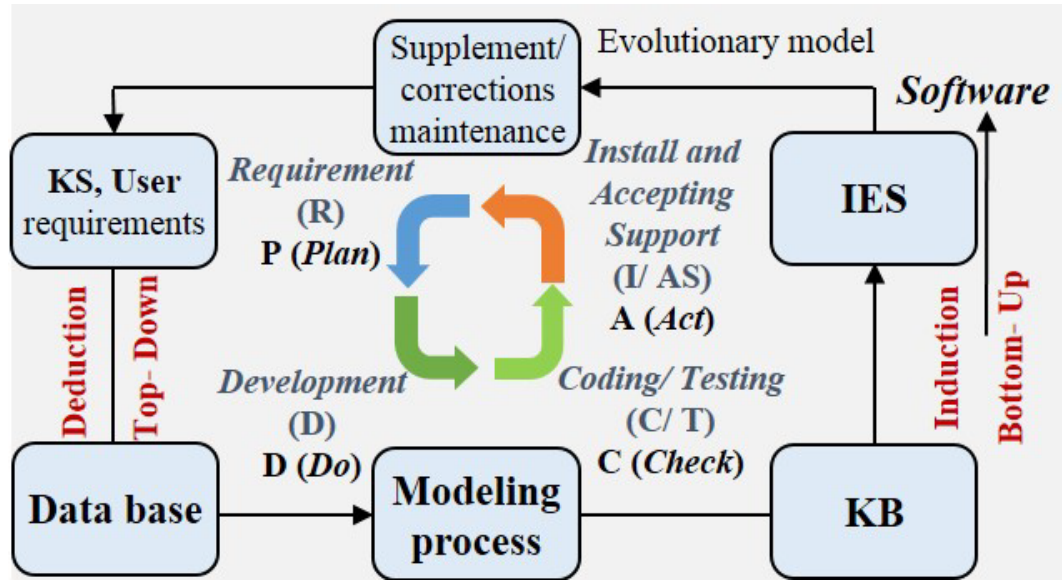

Fig. 1. PDCA in correlation with the methodologies: deduction, modelling, induction and standardised stages of software development (P-D-C/T-I/AS)

\subsection{Study Framework}

The first research framework refers to the international (ISO) and national (SRPS) standards. Using the standardisation platform, the paper covers knowledge sources Iqs (KS) in the form of global (Iqs/Iso) and local (Iqs/sRps) standards, IqS/(ISO+SRPS)/2017 $>90,000 \mathrm{KS}$. For the total statistical sample $\sum$ Iqs (KS), where ICS1= 1 - 99, the following relation applies (1):

$$
\sum_{\mathrm{ICS} 1} \mathrm{Iqs}(\mathrm{KS})=\sum_{\mathrm{ICS} 1} \mathrm{Iqs} / \mathrm{ISO}+\sum_{\mathrm{ICS} 1} \mathrm{Iqs} / \mathrm{SRPS}
$$

The second framework is the survey research, which included students/ master professors of TI of the SP IAS TI, i.e. a population of more than 80 survey participants.

The ICS1 fields analysed for high innovativeness intensity - Manufacturing Engineering $($ ICS1 = 25) and IT (ICS1 = 35) - represent two key fields of technics and informatics studies. According to the International Classification of Standards (ICS), the fields are classified into 
subfields which constitute domain knowledge 2 (DK2/ ICS2) and into further subfields which constitute domain knowledge 3 (DK3/ ICS3).

Grouping/clustering into standardised fields is done on the basis of frequent innovations which are expressed by quantities (Iq) and values (Iv) of knowledge base units [32]. On the basis of the International Classification of Standards and the research methodology, all standardised fields are grouped according to the level of innovativeness into the following clusters: daily, weekly, monthly, yearly and a cluster without innovativeness. Within the standardised fields, various numbers of higher education courses (Iqs/HE) SP IAS TI are present.

Total statistical knowledge sources for the informatics segment, i.e. IT (ICS1 = 35), designated as Iqs/CS1=35, include knowledge sources in the international (ISO) and national (SRPS) standards. For the intensity of innovativeness the following relation was applied (2):

$$
\mathrm{Ii}_{/ \mathrm{t}}=\mathrm{Iqu}_{/ \mathrm{ISO} / \mathrm{t}}+\mathrm{Iqp}_{/ \mathrm{SRPS} / \mathrm{t}-1}
$$

where: Iqu - number of ISO projects during different development phases at the beginning of the year $(\mathrm{t})$, and Iqp - number of published SRPS standards during the previous year $(\mathrm{t}-1)$.

On the basis of the results for the intensity of innovativeness, all the fields are grouped into innovativeness clusters, and according to the relations (3.1 - 3.5), wherein the clusters of daily innovativeness include 50 working weeks a year and five working days every week:

$$
\begin{gathered}
\mathrm{Ii}>250 \text { - innovations daily } \\
50<\mathrm{Ii} \leq 250 \text { - weekly innovation cluster } \\
12<\mathrm{Ii} \leq 50 \text { - monthly innovation cluster } \\
0<\mathrm{Ii} \leq 12 \text { - yearly innovation cluster } \\
\text { Ii }=0 \text { - no innovation }
\end{gathered}
$$

\section{Research Results}

The research results include the analysis of correlations of knowledge sources in the standardised fields within technics and informatics studies and courses of the SP IAS TI, as well as the possibilities for knowledge innovation in this SP (which leads to the title of TI professor, with 300 ESPB). The results of the analysis indicate how this SP follows international (ISO) and national (SRPS) standards and to what extent the courses of this SP are in correlation with education standards. The research was conducted in Serbia, at the Faculty of Technical Sciences in Čačak, University of Kragujevac.

The standards of overall innovation are grouped into specific fields, according to ICS, where ICS1 = 01 to 99, Fig. 2 (Iqs/ICS1 - sample in each standardisation field, January 2014), [14]. The survey was conducted with courses of the SP IAS, grouped into five segments:

I - courses within the studies of technics (TT-field),

II - courses within the studies of informatics / IT (IMT-studies),

III - Psychological - Pedagogical - Methodical courses (PPM - DH-field),

IV - a group of courses from the science and mathematics field (PM-field),

$\mathrm{V}$ - general education courses. 


\subsection{An Excerpt from the Research Results in Separate Standardised Fields (ISO - SRPS)}

The analysis of the results of the annual population sample research includes statistical time series (for example, 2016/01/01, with IqS/ISO+SRPS/2016.1.1 $=90.333$ ) of knowledge sources

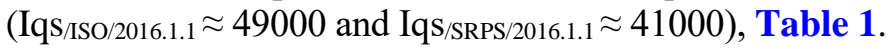

Table 1. Trend analysis of knowledge sources of the total standard population (ISO - SRPS)

\begin{tabular}{|c|c|c|c|c|c|c|c|}
\hline ICS1 (01-99) & \multicolumn{2}{|c|}{$\begin{array}{c}\text { Samples } \\
\text { (? Iqs) }\end{array}$} & \multicolumn{2}{c|}{$\begin{array}{c}\text { Published } \\
\text { (Iqp) }\end{array}$} & $\begin{array}{c}\text { Under } \\
\text { development } \\
\text { (Iqu) }\end{array}$ & \multicolumn{2}{c|}{$\begin{array}{c}\text { (CHF) } \\
\text { ? Iv }\end{array}$} \\
\hline \hline Year/month/day & ISO & SRPS & ISO & SRPS & ISO & ISO & SRPS \\
\hline$(1)$ & $(2)$ & $(3)$ & $(4)$ & $(5)$ & $(6)$ & $(7)$ & $(8)$ \\
\hline $2013 / 01 / 01$ & 41141 & 31191 & 21768 & 25523 & 4233 & 2968334 & 757636 \\
\hline $2014 / 01 / 01$ & Figure 1 & Figure 1 & 23025 & 29181 & 4744 & 1867564 & 805272 \\
\hline $2015 / 01 / 01$ & 46162 & 40130 & 24149 & 31105 & 4335 & 1779481 & 844797 \\
\hline $2016 / 01 / 01$ & 48879 & 41454 & 24864 & 32429 & 4732 & 2139002 & 828636 \\
\hline
\end{tabular}

Value indices (Iv) of sampled knowledge sources indicate and prove certain dilemmas in the accreditation processes and complementary expertise in higher education. Total values of the analysed sources $\sum$ Iv (ISO and SRPS) are about three million CHF (CHF being the Swiss currency or a cumulative index value of $\sum \mathbf{I v} \approx 3 * 10^{6}$ euros), Table 1 (columns (7) and (8)). Fig. 2 shows the (initial) annual comparative sample in separate fields, Iqs (sum of ISO and SRPS, $\sum \mathrm{IqS}_{/ / \mathrm{ISO} / 2014} \approx 44000$ and $\sum \mathrm{IqS}_{/ \mathrm{SRPS} / 2014} \approx 32000$, Table 1, columns (2) and (3)), [25].

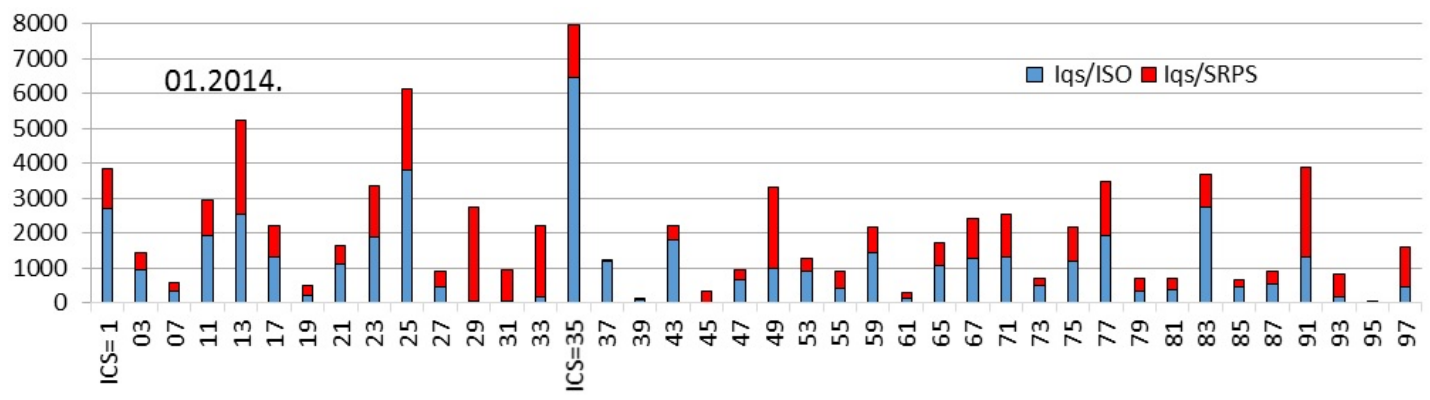

Fig. 2. Comparative analysis (ISO-SRPS) sources of knowledge - samples (Iqs) standards, 2014/ January

The examples of clustering of subfields within IT/informatics, presented in Micić et al. [34] are given on the population of knowledge source of a time series (Fig. 2), as well as in Micić et al. [35] from 2012/1(Iqs/2012.01) and in Ružičić and Micić [26] from 2013/1(Iqs/2013.01). The clustering carried out on a new sample, with the methodology presented in Micić and Ružičić [36], is shown on the examples of daily, weekly, monthly and annual frequencies of innovativeness. 
Table 2. Fields within TT-science with daily intensity of knowledge sources innovativeness

\begin{tabular}{|c|c|c|c|c|c|c|}
\hline & ICS1 & $\mathbf{I i} / 2014$ & Name of standardization field (TT-fields) & $\begin{array}{l}\text { Iqs/SO/ } \\
2016.1 .1\end{array}$ & $\begin{array}{c}\text { Iq S/SRPS/201 } \\
7.1 .1\end{array}$ & $\begin{array}{c} \\
\text { Iqs } \mathbf{s} \text { SO+S } \\
\text { RPS } \\
\end{array}$ \\
\hline (1) & (2) & (3) & (4) & $(5)$ & $(6)$ & $(7)$ \\
\hline 1 & 35 & 1166 & Information technology & 7023 & 2110 & 8942 \\
\hline 2 & 25 & 758 & Manufacturyng engin eering & 4059 & 2685 & 6639 \\
\hline 3 & 91 & 597 & Construction materials and building & 1438 & 3214 & 4500 \\
\hline 4 & 83 & 452 & Rubber and plastic industries & 2941 & 1153 & 4042 \\
\hline 5 & 23 & 376 & Fluid systems and components for general use & 2017 & 1802 & 3719 \\
\hline 6 & 77 & 448 & Metallurgy & 2012 & 1769 & 3686 \\
\hline 7 & 49 & 1063 & Aircraft and space vehicle engineering & 1103 & 2652 & 3510 \\
\hline 8 & 29 & 407 & Electrical engineering & 71 & 3228 & 3148 \\
\hline 9 & 33 & 658 & $\begin{array}{l}\text { Telecommunications. Audio and video } \\
\text { engineering }\end{array}$ & 201 & 2726 & 2694 \\
\hline 10 & 75 & 429 & Petroleum and related technologies & 1241 & 1254 & 2403 \\
\hline 11 & 59 & 308 & Textile and leather technology & 1509 & 927 & 2361 \\
\hline
\end{tabular}

Along with the explicitly mentioned fields of innovation (TT-fields) with daily intensity of innovativeness (Table 2), standardised fields of weekly intensity of innovativeness are also analysed, which are more detailed in comparison to the fields of monthly innovativeness intensity (according to Ii, Fig. 3) [33].

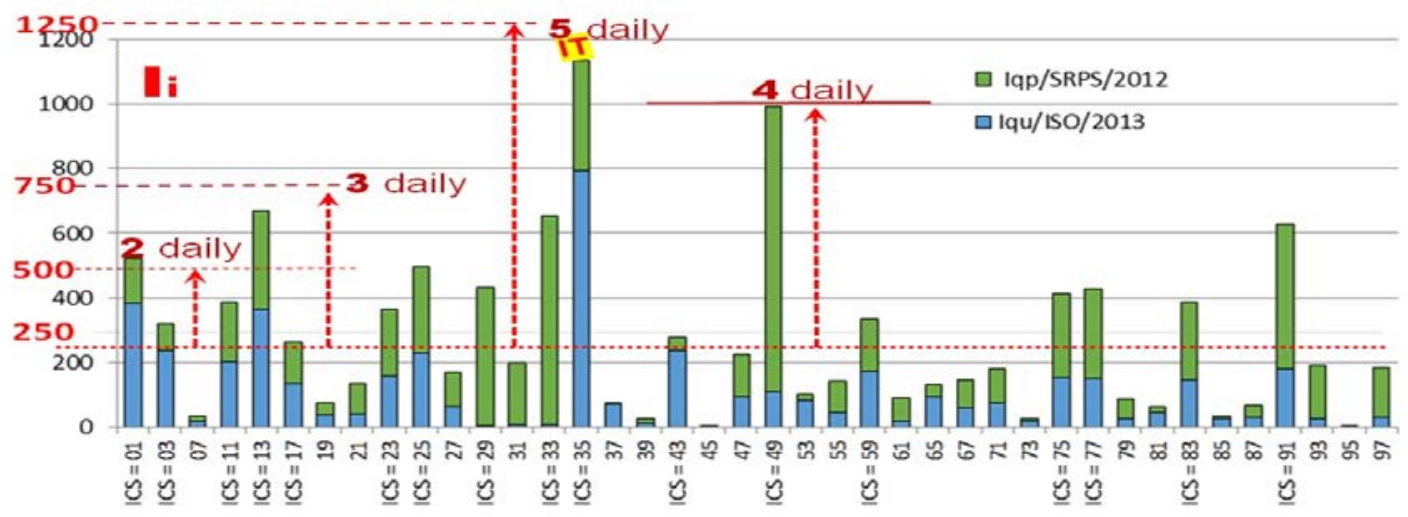

Fig. 3. Comparative analysis of annual amount of innovations of ISO-SRPS knowledge sources on the examples of global ISO innovations (Iqu) and local SRPS publications (Iqp)

Having analysed the courses of the SP IAS TI and fields of ISO and SRPS standardisation for all the courses of SP, the analysis of the presence of ICS1 fields from technics studies of weekly innovativeness is presented. For example, the fields of weekly innovativeness (annual statistical series from 2016), and the corresponding courses of importance to KM, in the case of the SP IAS TI are as follows: ICS1 = 03_Services - Company organisation, management and quality; Transport - (Quality management, Organisation of work, Trainee Programme); 17_Metrology and measurement - Physical phenomena (Physical Fundamentals of Electrical Engineering); 21_Mechanical systems and components for general use (Machine Elements); 27_Energy and heat transfer engineering (Thermotechnics, Renewable Energy); 43_Road vehicles engineering (Transportation and traffic systems); 71_Chemical technology (Chemical Technology); 93_Civil engineering (Architecture, urban planning and construction, Technical mechanics 1, Technical mechanics 2). 


\subsection{An Excerpt from the Results of the Survey Research}

Comparative analysis of the survey results via statistical data processing for informatics and technics segments of the SP IAS TI and subfields (courses) informatics/ IT and technics indicates the low frequency of the examples of innovativeness monitoring [25].

Considering the need for consistent daily, weekly or monthly knowledge acquisition, the analysis of the frequency of knowledge innovation with TI students was carried out. The results related to the informatics segment were chosen from the analysis to be analysed. The analysis of the results of the survey research on knowledge innovation frequency indicates the frequency (Fig. 4) for: a) all subfields (courses) on informatics studies, and b) one course of daily innovativeness (Organisation of computer systems) within informatics studies.

a) Innovation knowledge - all courses within informatics studies

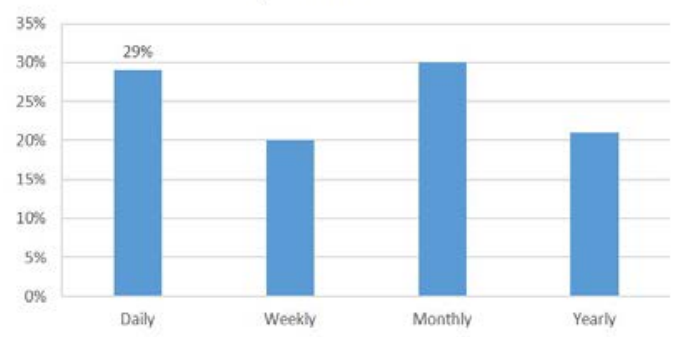

b) Innovation knowledge - course Organization of computer systems

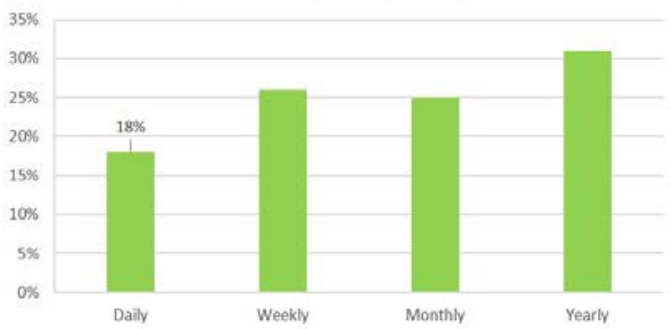

Fig. 4. Frequency of knowledge innovation (daily) with the students of the SP IAS TI, daily innovation: a) all courses within informatics studies, b) course Organisation of computer systems

High frequency of daily knowledge innovation has been determined on the basis of the results of the survey analysis: 29\% within all courses (Fig. 4a) and 18\% within one course (Fig. 4b) within the informatics segment. The possibility of course innovation monitoring for daily innovativeness within the informatics segment of the SP IAS TI was chosen from the research data to be analysed.

The results of the comparative analysis of knowledge innovation frequency, developmental teaching processes and educational goals in correlation with the standards enable modelling of $\mathrm{KM}$ on the standardisation platform. KM modelling will improve study programmes in the next accreditation cycle. Frequent innovations within the standardised thematic fields (daily, weekly, monthly or annually) indicate the need for necessary changes of SP, and for KB and KBS software designed for KM.

The analysis of the results of the survey of weekly intensity of knowledge innovation determined the frequency of knowledge innovation with students for the courses within the technics studies which belong to the standardised fields ICS1 = 27 and ICS1 = 43 (Fig. 5): a) Thermotechnics and b) Transportation and traffic systems. 

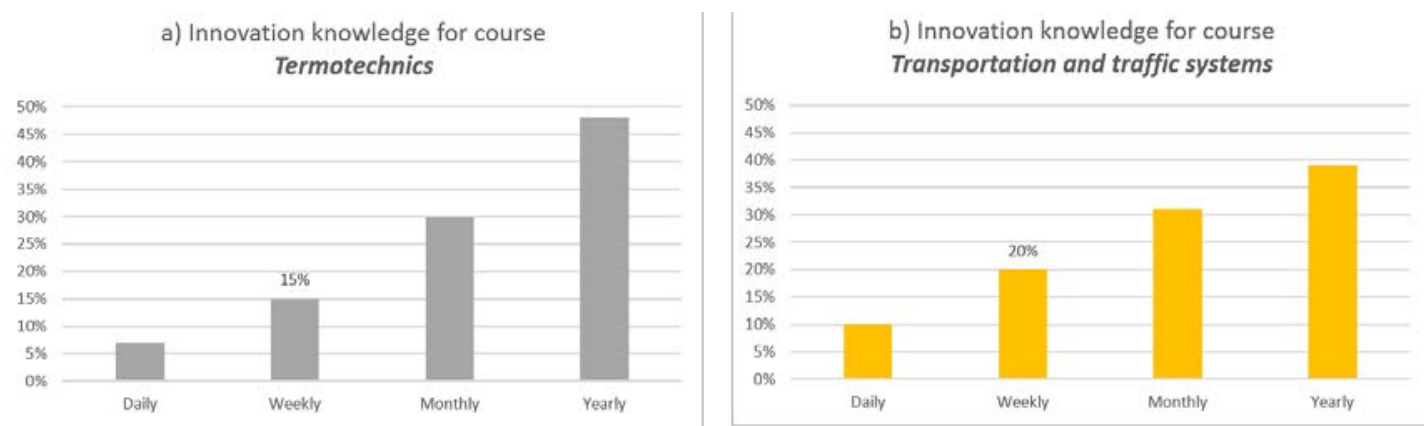

Fig. 5. Knowledge innovation frequency with students of the SP IAS TI for courses from the field of technics, weekly innovation: a) Thermotechnics (ICS1 = 27), b) Transportation and traffic systems

$$
(\mathrm{ICS} 1=43)
$$

On the basis of the above-mentioned ICS1 fields/courses of weekly innovativeness, as well as on the basis of frequency results on the examples of knowledge innovation and innovation monitoring for the courses which belong to the fields ICS1 $=27$ and ICS1 $=43$ (Fig. 5), the conclusion can be drawn that knowledge innovation amongst the students of technics in the SP TI is unsatisfactory.

\section{Discussion of the Results in Correlation with Standardisation (ISO-SRPS), SP/courses and Software Development for KM}

The analysis of the correlations of knowledge sources in the standardised fields that are present in the segments of technics and informatics and courses of the SP IAS TI is presented. The correlations mentioned above are analysed from other aspects in terms of the need and possibilities for knowledge innovation in this SP (which confers the title of TI professor, with 300 ESPB). The results of standardisation correlation (global - ISO and local - SRPS) and $\mathrm{SP} /$ courses are presented through:

- the original comparative values of global and local knowledge sources in the standardised fields (on the basis of innovativeness intensity), and

- the measures of knowledge source frequency within the segment/studies of technics and informatics (determined on the basis of the survey results).

Special attention is paid to the analysis of compatibility and presence/representation of the courses in the first two segments of these two-course studies (I - technics and II - informatics). Summarised results of the analysis of international (ISO) and national (SRPS) standardisation are given in correlation with the results of the survey research into the examples of this study programme. Standardisation platform innovations in the field of Information and Communications Technology (ICT) for the knowledge quality are observed using the PDCA concept [35]. Innovativeness intensity in correlation with standardisation (ISO-SRPS) and SP/courses is also observed using the PDCA concept, as follows: Plan - resources, products and services planning; $\underline{D o}$ - development of methodology and models; $\underline{C h e c k}$ - accreditation checks of the SP; $\underline{A} c t$ - improvements of the SP on the standardisation platform.

On the basis of the results and the analysis of survey data on the intensity of innovation, within all five segments of the IAS TI study programme, a low frequency of possibility of innovation monitoring has been determined $(33.10 \%$ of the respondents are able to fully monitor innovation). From the above-mentioned results, as well as from Fig.s $\mathbf{2}$ and 3, there now follows: the analysis of standardised fields in correlation with courses of daily 
innovativeness within the segments of technics and informatics (Section 5.1), proposals for modelling KBS innovation for KM through the development and application of software (Section 5.2) and a concluding discussion of the results (Section 6).

Figure 6 presents the elements significant for KM. These elements are presented in several dimensions. The diagram represents the relationship between all the aspects that will be discussed (the concepts KM, PDCA, international standard, local standard, innovations, etc.).

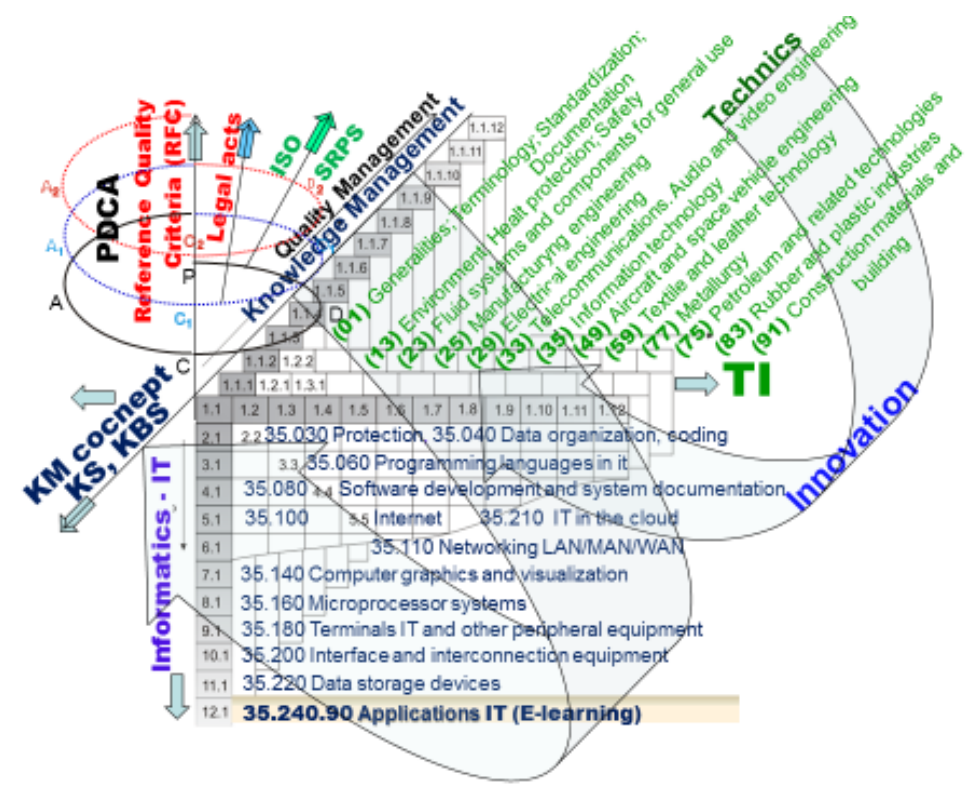

Fig. 6. Relationship between all the aspects that will be discussed

\subsection{KM in Correlation with Standardised Fields and Technics and Informatics Courses of Daily Innovativeness}

Two key ICS1 fields of importance to KM were selected from within the technics and informatics segment of SP TI. These two fields, where innovations on the standardisation platform (ISO and SRPS) occur on a daily basis (according to the index of innovativeness $\mathrm{Ii}_{\text {/year }}$ ) are most frequent in the SP IAS TI:

- Manufacturing engineering, an example for the technics segment,

- Information technology, for the informatics segment, Table 3.

Table 3. Fields ICS1/courses of the SP IAS TI of daily innovation in all analysed years

\begin{tabular}{|c|c|c|c|c|c|c|c|c|c|}
\hline \multicolumn{10}{|c|}{ 2013-2014-2015-2016 } \\
\hline & ICS1 & $\begin{array}{c}\mathbf{I} \mathbf{i}_{(\mathrm{Std}+\mathrm{Amd}+} \\
\text { Cor) } \\
/ 2016\end{array}$ & $\begin{array}{c}\text { Name of } \\
\text { standardization } \\
\text { field }\end{array}$ & \begin{tabular}{|c|} 
IqS/ISO/ \\
2016
\end{tabular} & $\mid \begin{array}{c}\text { Iq S/SRPS } \\
2016\end{array}$ & $\mathbf{I i}_{2014}$ & $\mathbf{I i}_{2015}$ & $\mathbf{I i}_{2016}$ & $\begin{array}{c}\text { Courses of two-course } \\
\text { studies (IMT)/ SP } \\
\text { IAS TI, Iqs/HE }\end{array}$ \\
\hline (1) & (2) & (3) & (4) & (5) & (6) & (7) & (8) & (9) & $(10)$ \\
\hline 1. & 35 & 931 & $\begin{array}{c}\text { Information } \\
\text { technology }\end{array}$ & 7023 & 1919 & 1166 & 916 & 831 & $\begin{array}{l}13 \text { courses from the } \\
\text { field of informatics }\end{array}$ \\
\hline 2. & 25 & 452 & $\begin{array}{l}\text { Manufacturing } \\
\text { engineering }\end{array}$ & 4059 & 2580 & 758 & 436 & 446 & $\begin{array}{l}\text { nine courses from the } \\
\text { field of technics }\end{array}$ \\
\hline
\end{tabular}


The index of innovativeness of the IT field in $2016 \mathrm{Ii}_{/ 35 / 2016}=831$ (column (9)) includes only published standards (Std), while $\mathrm{Ii}_{/ 35 / 2016}=931$ (column (3)) includes all standardised knowledge sources (Std and amendments [designated as "Amd"] and corrections [designated as "Cor"] in ISO organisation), Table 3.

Within the SP IAS TI there are 13 courses in the informatics segment which have daily innovativeness and belong to ICS standardisation fields: Information technology, Introduction to programming, Programming languages, Object-oriented programming, Information systems, Operation systems, Internet programming, Web technologies, Computer networks and communication, Organisation of computer systems, E-learning, Information technology in education, Databases. The technics segment is represented through nine courses: Production systems, CAD/ CAM technology, CAD/ CAE design, Programming control of machines, Technological processes, Introduction to technical systems, Robots and manipulators, Process automation, Automatic production line.

The analysis of correlations between the standards and the SP shows that competence assessments are the result of the standardised fields to which other courses of the accredited SP IAS TI belong. An example of less present courses within the standardised fields is given below, Table 4.

Table 4. Less present fields of technics studies (daily innovation), within the courses of the SP IAS TI

\begin{tabular}{|c|c|c|c|c|c|c|}
\hline & ICS1 & $\mathbf{I i}_{2016}$ & Name of standardization fields & Iqs/so & IqS/SRPS & $\begin{array}{c}\text { Courses SP IAS TI } \\
\text { Iq S/HE/CSI=1 }\end{array}$ \\
\hline \hline$(1)$ & $(2)$ & $(3)$ & $(4)$ & $(5)$ & $(6)$ & $(7)$ \\
\hline 1. & 13 & 578 & $\begin{array}{c}\text { Environment; Healt protection; } \\
\text { Safety }\end{array}$ & 2802 & 3070 & Ecology \\
\hline 2. & 01 & 399 & $\begin{array}{c}\text { Generalities; Terminology; } \\
\text { Standardization; Documentation }\end{array}$ & 2708 & 1324 & $\begin{array}{c}\text { Technical drawing and } \\
\text { modeling }\end{array}$ \\
\hline 3. & 91 & 391 & $\begin{array}{c}\text { Construction materials and } \\
\text { building }\end{array}$ & 1438 & 3062 & $\begin{array}{c}\text { Mechanical modeling } \\
\text { and computer simulation }\end{array}$ \\
\hline 4. & 29 & 270 & Electrical engineering & 71 & 3077 & $\begin{array}{c}\text { Applied electrical power } \\
\text { engineering }\end{array}$ \\
\hline
\end{tabular}

However, an examination of the literature references [25] of the already mentioned courses reveals a mismatch among the courses in terms of complying with ISO and SRPS standardisation. Some ICS1 fields with daily innovativeness within technics studies are not present in the SP IAS TI, Table 5.

Table 5. ICS1 fields not present within the studies of technics (daily innovation, 2016) in the SP IAS TI,

$\mathrm{IqS}_{/ \mathrm{HE}}=0$

\begin{tabular}{|l|c|c|c|c|c|}
\hline & ICS1 & Ii2016 & $\begin{array}{c}\text { Name of standardization field } \\
\text { ICS1 }\end{array}$ & Iqsaso & Iqsıso \\
\hline \hline$(1)$ & $(2)$ & $(3)$ & $(4)$ & $(5)$ & $(6)$ \\
\hline 1. & 23 & 319 & Fluid systems and components for general use & 2017 & 1702 \\
\hline 2. & 83 & 310 & Rubber and plastic industries & 2941 & 1101 \\
\hline 3. & 33 & 257 & Telecommunications; Audio and video engineering & 201 & 2493 \\
\hline
\end{tabular}


Having in mind previously shown results, starting from knowledge sources (KS) (relation (1)), trend analyses of knowledge sources of the overall population of standards (ISO - SRPS), (Table 1), intensity of innovativeness (relation (2)) and innovativeness cluster (towards (3.1) (3.5)), the correlation between the standardised fields and courses of the SP TI for KM is determined. The results of the survey research and determined measures of knowledge innovation frequency with students within studies of technics and informatics, in correlation with the statistical sample of knowledge source (Iqs) (columns (5) and (6)) and intensity index (Ii), (column (3)), Tables $2-5$, indicate the importance of connection between the process of knowledge acquisition and the use of global and local standards for KM.

The correlations between the study programmes and ISO - SRPS standardisation from the aspect of deduction (including H1 through the Plan and Do phases of the PDCA approach) emphasise the need for knowledge modelling and $\mathrm{KM}$ with the aim of continuous innovation monitoring within the standardised fields.

( Plan-phase) From the aspect of the quality assurance of study programmes, elaboration and application of national (SRPS) standards, aligned with international standards (ISO), in correlation with educational standards [5], are of fundamental importance for KM in resource planning. Given that the students of the SP IAS TI acquire the title of professor of technics and informatics, with $300 \mathrm{ESPB}$, and are then qualified for professional performance in various business systems and for providing technical-IT support in a large number of fields/subfields, it is highly important that the study programme follows international and national standards. The results of the survey data analysis show a high frequency of the need for the application of the standards during education and for knowledge innovation within both segments, technics (53.34\%) and informatics (61.13\%). Bylaws for accreditation of the SP [5] do not sufficiently follow ISO-SRPS standards or practice and industry requirements for product development on the platform ISO/IEC-SRPS. The results of the above-mentioned research lead to some conclusions regarding the problem of compatibility of the SP (expected outcomes and competences) on one side, and standards (SRPS and ISO) on the other, as well as new standards in education.

(Do-phase) On the basis of the index of published (Iqp) global (ISO) and local (SRPS) documents and the value of global developmental projects quantity index (Iqu), the growth of knowledge source $\left(\Delta \mathrm{KS}_{/ \mathrm{ICS} / \mathrm{t} /}\right)$ is determined, for a specific time period $t$ in the domain field DK1/ ICS1 (Fig. 3). The total growth of knowledge sources and the growth of the knowledge base contribute to $\mathrm{KM}$, on the basis of the innovativeness index (Ii), in accordance to the relation (2). The need for the resources and KM is conditioned by the obligation to apply ISO - SRPS standards on technics and informatics studies, which is of particular importance for teaching staff and educational institutions. The correlations of the SP and global and local standards are determined on the basis of the results of the analysis of comparative quantity indices of global (Iqs/ISo) and local (Iqs/sRPs) standardised KS of statistical annual time series of all ICS1 fields (Figs. 2 and 3), as well as on the basis of the frequency of knowledge innovation among the students of the SP IAS TI (Figures 4 and 5). Determining the correlation between the standardised fields and courses of technics and informatics studies enables a timely impact on the provision of KM and advancement of the SP for the quality of knowledge of future and present students in these standardised fields.

As in the paper [41], Fig. 7 presents an evolutionary model of software development, with the standardised labels (for software lifecycle, according to ISO and SRPS standards [40]) for: requirements (R1, R2, .. Rn); development (D); coding/testing (C/T); installation and acceptance support (I/AS). In the PDCA spiral for continuous quality improvement or in the PCDA concept or methodology each step from each PDCA phase is accompanied with the 
activities and tasks grouped through R-D-C/T-I/AS, respectively (Figure 6b, by deduction, from top to bottom, from general facts to data bases and knowledge base, and by induction, from knowledge base to problem solving).
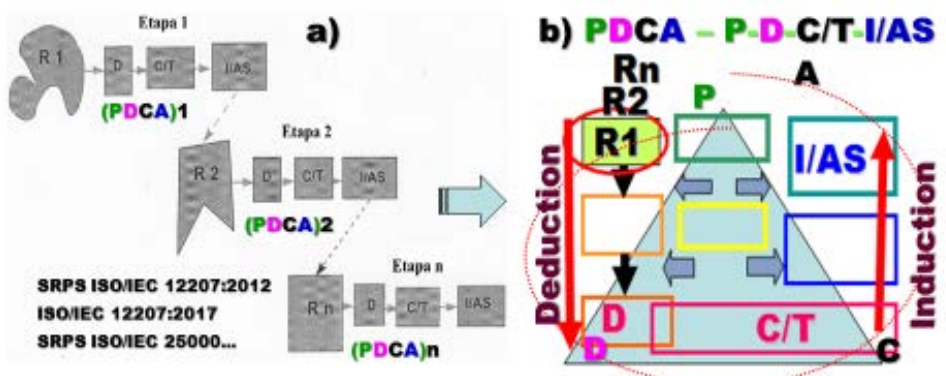

Fig. 7. Software lifecycle: a) according to SRPS and ISO/IEC standards [41]; b) in PDCA concept

\subsection{KBS Innovation for KM Achieved by Software Development and Use}

Innovation in the knowledge base system (KBS) on the basis of the original sample of more than 90,000 standardised sources (which are binding in a country) in correlation with the SP TI contributes to KM and to the improvement of study programmes and teaching processes in HE. The overall results of the analysis enable the development of a methodology for the establishment of appropriate correlations between the standardised fields and courses of the SP TI, at higher education level [41]. On the basis of correlations between the standardised fields and the frequency of knowledge innovation amongst the students of the SP IAS TI within informatics courses of daily innovativeness (Section 4.1, Fig. 4) and technics courses of weekly innovativeness (Section 4.1, Fig. 5), the need for KM development and the use of software can be determined [42].

In comparison to the other standardised fields present in the SP TI, the IT field (ICS1 = 35) is highly innovative on the standardisation platform $-\mathrm{Ii}_{35 / 2016}=1166$ standards (Table 2, Fig. 3). The innovation of KBS for knowledge management in standardised fields involves the development of additional modules organised in accordance with the functional principle of the knowledge base. By using the software developed for KM it is possible to create a KBS for daily monitoring of knowledge innovativeness in all fields with high intensity innovativeness [20].

By developing the software for KM in correlation with innovation of KBS, depending on the users' goals and needs, it would be possible to have automated solutions in different ICS fields. Within the software (IES) there would be an ES KM model that would enable the creation of the domain field DK1 of the standardised fields, the creation of rules and solving tasks and problems (Fig. 8). 


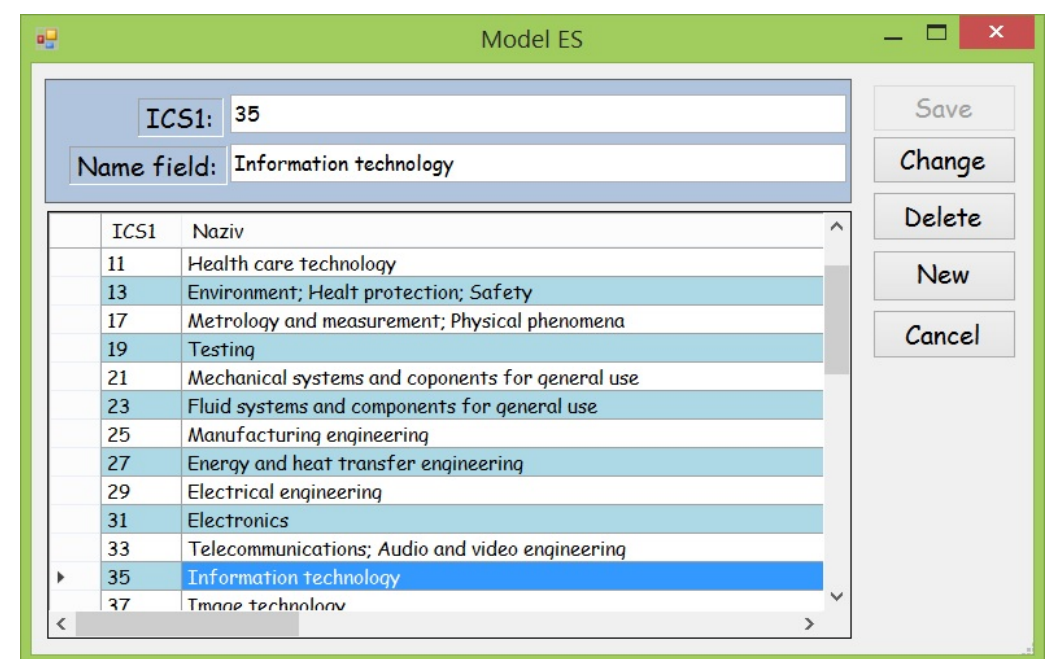

Fig. 8. The creation of objects/domain field DK1 in model of ES software for KM and use of ICS1

Through the development and use of the software for KM, from the aspect of induction (including H2, through Check and Act phases of the PDCA approach), an emphasis is placed on the possibilities of knowledge innovation, effective tracking of SP innovativeness and improvements in higher education [39].

ES software is an application which enables the assessment of $\mathrm{KM}$ for knowledge innovation in all standardised fields (ICS1 $=01,03$, up to 99). The software is an integral part of the creation of a strategic national knowledge architecture, [33], in the correlation with the assessment of KM.

The software should provide mass access to knowledge sources (teachers, students), which will ultimately have a greater impact on society since the students of the SP TI are future teachers in primary and secondary schools. The application of the specified software application and enabled online access to the knowledge sources in the target field (first of all, the teachers) could efficiently solve the problem of accessing KS and innovating KB on a daily basis.

The software solution should be first implemented in the academic Internet network for the educating institutions founded by the state. Limited access (for non-commercial purposes, with the protection of the licenced copyrights) should be provided by the Internet technologies. The software provides an explicit link to KM assessment in correlation with the higher education and global and local standardisation. The software base incorporates the possibility of choosing within all the fields and subfields of ICSU in the form of intelligent software systems in the form of ES:

- ICS1 - 40 fields,

- ICS2 - 392 subfields and

- ICS3 - 909 subsubfields.

(Check-phase) The period for checks (Check) of innovativeness in certain fields/subfields depends on the total time growth of knowledge base innovativeness. Within all the fields with a high innovativeness index (Ii), after accreditation of the SP it is necessary to carry out annual checks of the SP innovativeness level (especially if the accreditation is valid for several years). Innovation (KBS) and the use of software for KM will only be widely implemented with success if the knowledge base is based on the domain field and is regularly and systematically updated. 
( Act-phase) Improvements in higher education and in the SP (measurable at least annually) in relation to the standardisation platforms necessitate the development of the software for KM which will allow access to ISO-SRPS standards and monitoring of relevant correlations with the SP. The realisation of the goals from knowledge planning, collecting and updating, from knowledge sources to implementation, in the fields with high innovativeness intensity, is beyond the capacity of an individual. On the basis of innovativeness intensity (relation (2)), the software for KM automatically determines to which innovativeness cluster a field belongs, for any time series of knowledge sources. An Expert System model with predetermined rules and $\mathrm{KB}$ enables $\mathrm{KM}$ in higher education.

The software can provide access to knowledge sources for KM in different fields on the standardisation platform. The software represents an invaluable source of support to experts for professional work and KM through all HE processes: research, product development, education, as in the SP example given above.

\section{Conclusion}

This paper presents the original results of $\mathrm{KM}$ on the basis of the analysis of the results of knowledge source correlations in ICS fields and courses. Original frequency measures of knowledge innovation within TI studies are determined (on the basis of the results of comparative research). On the basis of the research results (the survey research and the standardisation aspect), this research shows the importance of correlation between the processes of knowledge acquisition, the application of international and national standards, and KM.

This study has contributed an original comparison of global (ISO) and local (SRPS) knowledge sources in ICS1 fields against knowledge innovation within the studies of technics and informatics of the SP IAS TI. The results of this research, from the aspects of standardisation and survey data, show the significance for KM in higher education of the connection between the process of acquiring competencies (outcome and knowledge) and the implementation of global and local standards. On the basis of a multicriteria statistical analysis, a significant step in knowledge innovation was made within the technics and informatics segments of the SP TI. The results were presented with the aim of improving KM on the basis of the standardised fields with high innovativeness intensity of KS and the proof of the initial hypotheses. On the basis of the PDCA, it is possible to offer conclusions from two aspects:

- Deduction, including resource, products and service planning (Plan) and development of methodology and models (Do)

- Induction, including accreditation checks of SP (Check) and improvement of SP on the standardisation platform (Act).

1. (Plan - Do) The methodology and model development start from an overall statistical sample Iqs (KS) in ICS fields in various phases of product development. On the basis of Iqu/ISo and Iqp/sRPs and innovativeness intensity $\mathrm{Ii}_{\mathrm{t} / \mathrm{t}}$ it is determined to which innovativeness cluster a field belongs. KM will be improved if the new software created for higher education needs at least partly follows national and international standards. It is necessary that the creators of the SP (teachers, associates) first know and then include the standards (ISO - SRPS) into the curricula of SP (through goals, outcomes and course contents, and through practical teaching and literature references). KM is possible on the basis of the correlations between study programmes and global and local standards. Knowledge innovativeness intensity in higher education falls significantly behind the standardisation intensity ( $\mathrm{Ii}_{\text {/SO-SRPS }}$ ); the reasons for this should be the subject of future research. 
2. (Check-Act) KM, on the examples of technics and informatics studies in correlation with the original comparative values of global (ISO) and local (SRPS) knowledge sources, enhances study programmes (at the level of QMA and QAA) for users within the fields on the standardisation platform. Improvements of the relations of innovativeness ( $\mathrm{Ii}_{\text {HE }}$ and $\mathrm{Ii}_{\text {/ISO-SRPS }}$ ) for the benefit of the education society must begin by the application of legal obligations, bylaws, innovation of standards in education, and innovation of knowledge by the use of software for KM, etc. By using the software for KM, resource availability is improved in the fields with high innovativeness. It is necessary to systematically and continuously monitor knowledge innovation trends in product innovations on the standardisation platforms, and, by improving KB and KBS, this becomes possible. The results of the analysis of the innovation model and paths of the knowledge base system based on the local (SRPS) platform utilising the PDCA/t concept, lead to the achievement of excellence in practice.

Implicit conclusions are strategically highly important for the introduction of quality management systems at the University of Kragujevac, as well as harmonization with standards - especially local ones. Furthermore, it is highly significant to define an Agreement with the Institute for Standardization of Serbia, to enable (students) to freely access local and global standards, in relevant subjects (which are correlated with intensively innovating standards) for each study program.

The operational activities and tasks that implicitly emerge from the analyzed results are as follows: consistency across the PDCA phases, in the fourth phase - the „Act” phase, the SP „Technics and Informatics” will be enhanced on the standardization platform.

Explicitly, there is no need to enroll students, in the previously mentioned SP „Technics and Informatics,” in the upcoming school years, starting from 2019/2020.

\section{References}

[1] Official Gazette, "The Law on Higher Education,” Belgrade, The Republic of Serbia, 2018. Article(CrossRefLink)

[2] ISO, "International Standards for Business, Government and Society, List of ICS fields" available at: https://www.iso.org/standards-catalogue/browse-by-ics.html, 2018, (accessed 1 February 2018). Article(CrossRefLink)

[3] ISS (2018), "Institute for Standardization of Serbia, Advanced search," available at: http://www.iss.rs/en/standard/advance_search.php. Article(CrossRefLink)

[4] Faculty of Technical Science, Čačak, University of Kragujevac, Integrated academic studies Technics and Informatics, http://ftn.kg.ac.rs/en/index.php?prikaz=program\&spr=IAS_TI, Article(CrossRefLink)

[5] CAQA - Commission for Accreditation and Quality Assurance, Serbia, http://www.kapk.org/en/home/, A guide through accredited institutions of higher education and study programs in Serbia https://drive.google.com/file/d/1XEtzHSkx1rH2eQi4V2NC01rmWWpYoBts/view (02.02.2018), Article(CrossRefLink)

[6] ISO/IEC, "2382-20:1990 Information technology - Vocabulary - Part 20: System development (15 pages)," in Switzerland, Geneva, 1990. Article(CrossRefLink)

[7] ISO/IEC, "2382-28:1995 Information technology - Vocabulary - Part 28: Artificial intelligence Basic concepts and expert systems (25 pages)," in Switzerland, Geneva, 1995. Article(CrossRefLink)

[8] ISO, "ISO 8402:1994 Quality management and quality assurance - Vocabulary (50 pages)," in Switzerland, Geneva, 1994. Article(CrossRefLink)

[9] ASQ (@ American Society for Quality), "Plan-Do-Check-Act (PDCA) Cycle," available at: http://asq.org/learn-about-quality/project-plannin, 2015, (accessed 16 January 2015). Article(CrossRefLink) 
[10] Heisig P., Suraj O. A., Kianto A., Kemboi C., Arrau G. P. and Easa N. F., "Knowledge management and business performance: global experts' views on future research needs,” Journal of Knowledge Management, Vol. 20, No. 6, pp. 1169-1198, 2016. Article(CrossRefLink)

[11] ISO/IEC, “2382-36:2008 Information technology - Vocabulary - Part 36: Learning, education and training (14 pages),” in Switzerland, Geneva, 2008. Article(CrossRefLink)

[12] Romanowski, M. H., "Neoliberalism and Western accreditation in the Middle East: A critical discourse analysis of Educational Leadership Constituent Council standards," Journal of Educational Administration, Vol. 55, No. 1, pp. 70-84, 2017. Article(CrossRefLink)

[13] Jun, W. and Hong, S., “A Study on Development of Quality Standards of Educational Smart Contents,” KSII Transactions on Internet and Information Systems, Vol. 8, No. 6, pp. 2152-2170, 27 June 2014. Article(CrossRefLink)

[14] Micić, Ž. and Ružičić, V., "Trends knowledge innovation standardized authorities in one of creativity with a focus on quality subfield," in Proc. of 10th International Symposium Research and Design for Industry - IIPP, Faculty of Mechanical Engineering, Belgrade, pp. 201-208, 1-13 December 2014. Article(CrossRefLink)

[15] Micić, Ž. and Blagojević, M., "Standardization of representation knowledge in IT," in Proc. of 6th International Symposium, Technology, Informatics And Education for Learning And Knowledge Society - TIO 6, University of Kragujevac, Faculty of Technical Sciences, Čačak, pp. 726-731, 2011. Article(CrossRefLink)

[16] Micić, Ž., "Modeling of education/e-learning process based on standardization and PDCA platform," in Proc. of National Conference with International Participation, Business Process Reengineering in Education - RPPO 2013, Faculty of Technical Sciences in Čačak, pp. 207-215, 20-22 September 2013. Article(CrossRefLink)

[17] Stanković, N. and Micić, Ž., "Innovating and management of the knowledge base on the example of IT applications," Telematics and Informatics, vol. 35, pp. 1461-1472, 2018. Article(CrossRefLink)

[18] Ružičić, V. and Micić, Ž., "Continuous monitoring the trends of knowledge sources per cluster innovation intensity,” in Proc. of 11th International Symposium Research and Design for Industry - IIPP, Faculty of Mechanical Engineering, Belgrade, pp. 114-123, 22-23 December 20172015.

[19] Katić, A., Kiš, T., Ćosić, I., Vukadinović, S. and Šeregelj, T. D., "Modelling the Composite Competitiveness Index of the Knowledge-based Society,” Acta Polytechnica Hungarica, Vol. 12, No. 1, pp. 229-249, 2015. Article(CrossRefLink)

[20] Micić, Ž. and Blagojević, M., "Knowledge acquisition in Information technology and software engineering toward excellence of information system based on standardisation platform," Computer Standards and Interfaces, Vol. 44, No. 1, pp. 1-17, 2016. Article(CrossRefLink)

[21] Tangaraja, G., Rasdi, R.M., Samah, B.A. and Ismail, M., "Knowledge sharing is knowledge, transfer: a misconception in the literature,” Journal of Knowledge Management, Vol. 20, No. 4, pp. 653-670, 2016. Article(CrossRefLink)

[22] Uden, L. and He, W., "How the Internet of Things can help knowledge management: a case study from the automotive domain,” Journal of Knowledge Management, Vol. 21, No. 1, pp. 57-70., 2017. Article(CrossRefLink)

[23] Silva, J. C., Matellib, J. A. and Bazzo, E., "Development of a knowledge-based system for cogeneration plant design: Verification, validation and lessons learned,” Knowledge-Based Systems, Vol. 67, pp. 230-243, 2014.

[24] Brass, J., "Standards-based governance of English teaching, past, present, and future?,” English Teaching: Practice \& Critique, Vol. 14, No. 3, pp. 241-259, 2015. Article(CrossRefLink)

[25] Micić, Ž., Tasić, D. and Debeljković, D., "Knowledge sources in areas standardized TT-science for the expertise in the accreditation process," in Proc. of XXIII Conference Trends of Development: "The situation of higher education and science in Serbia" - TREND 2017, University of Novi Sad, Faculty of Technical Sciences, Zlatibor, pp. 140-143, 22-24 February 2017.

[26] Ružičić, V. and Micić, Ž., "How study programmes accompany the international ISO and national SRPS standards?" in Proc. of XXIII Conference Trends of Development: "The situation of higher education and science in Serbia” - TREND 2017, University of Novi Sad, Faculty of Technical 
Sciences, Zlatibor, pp. 140-143, 22-24 February 2017.

[27] Chang, C. L. and Lin, T. C., "The role of organizational culture in the knowledge management process," Journal of Knowledge Management, Vol. 19, No. 3, pp. 433-455, 2015. Article(CrossRefLink)

[28] Bedford, D. and Harrison, F., "Leveraging environmental scanning methods to identify knowledge management activities in transportation,” Journal of Knowledge Management, Vol. 19, No. 3, pp. 579-592, 2015. Article(CrossRefLink)

[29] Shih, W. L., and Tsai, C. Y., "The effects of knowledge management capabilities on perceived school effectiveness in career and technical education,” Journal of Knowledge Management, Vol. 20, No. 6, pp. 1373-1392, 2016. Article(CrossRefLink)

[30] Song, B., Jiang, Z. and Li, X., "Modeling knowledge need awareness using the problematic situations elicited from questions and answers,” Knowledge-Based Systems, Vol. 75, pp. 173-183, 2015. Article(CrossRefLink)

[31] PSU (2004), “Cluster Analysis, Ward’s Method, (C) 2004" Pennsylvania State University, Pennsylvania, available at:

http://sites.stat.psu.edu/ ajw13/stat505/fa06/19_cluster/09_cluster_wards.html (accessed 1 February 2017).

[32] Blagojević M., Micić Ž. and Vujičić M., "Cluster Analysis of Knowledge Sources in Standardized Electrical Engineering Subfields,” Serbian Journal of Electrical Engineering, Fakultet tehničkih nauka Čačak, Vol. 3, No. 13, pp. 405-422, 2016. Article(CrossRefLink)

[33] Ružičić S. V. and Micić M. Ž., "Creating a strategic national knowledge architecture: A comparative analysis of knowledge source innovation in the ICS subfields of multimedia and IT security,” Computers \& Security, Vol. 70, pp. 455-466, 2017. Article(CrossRefLink)

[34] Micić, Ž., Stanković, N. and Blagojević, M., "Clustering of knowledge innovation in standardized "hardware's" subfields of information technology,” in Proc. of 5th International Conference on Information Technology and Development of Education, Idvor, pp. 319-326, 27 July 20142014. Article(CrossRefLink)

[35] Micić, Ž., Micić, M. and Blagojević, M., "ICT innovations at the platform of standardization for knowledge quality in PDCA,” Computer Standards \& Interfaces, Vol. 36, No. 1, pp. 231-243, 2013. Article(CrossRefLink)

[36] Micić, Ž. and Ružičić, V., "Innovation sources of knowledge for clustering standardized field of creativity," in Proc. of Technics and Informatics in Education - TIO 2016, University of Kragujevac, Faculty of Technical Sciences, Čačak, pp. 250-257, 28-29 May 2016. Article(CrossRefLink)

[37] Shin S., Jung H. and Yi Y. M., "Building a Business Knowledge Base by a Supervised Learning and Rule-Based Method,” KSII Transactions on Internet and Information Systems, Vol. 9, No. 1, pp. 407-420, 31 January 2015. Article(CrossRefLink)

[38] Chun S., “A Process-Centered Knowledge Model for Analysis of Technology Innovation Procedures,” KSII Transactions on Internet and Information Systems, Vol. 10, No. 3, pp. 1142-1453, 31 March 2016. Article(CrossRefLink)

[39] Micić, Ž. and Blagojević, M., "IT in education and entrepreneurship on the platform of national knowledge and quality architecture," in Proc. of $3^{\text {rd }}$ National Conference With International Participation, Faculty of Technical Sciences in Čačak, pp. 11-27, 24-25 March 2018. Article(CrossRefLink)

[40] Micić, Ž., Dolićanin Ć. and Milivojčević M., "Unique information system for quality assurance of study in Serbia,” XXIV TRENDOVI RAZVOJA: "Digitalizacija visokog obrazovanja", Kopaonik, pp. 21-23. 02. 4 April 2018.

[41] ISO/IEC (2017) "ISO/IEC/IEEE 12207:2017, Systems and software engineering -- Software life cycle processes" , (SRPS ISO/IEC 12207: 2012, Pages: 137, identical with ISO/IEC 12207: 2008 Withdrawn), in Switzerland, Geneva, 2017. Article(CrossRefLink)

[42] Baek, D., Lee, B. and Lee, J.-W., “Content-based Configuration Management System for Software Research and Development Document Artifacts,” KSII Transactions on Internet and Information Systems, Vol. 10, No. 3, pp. 1404-1415, 27 March 2016. Article(CrossRefLink) 


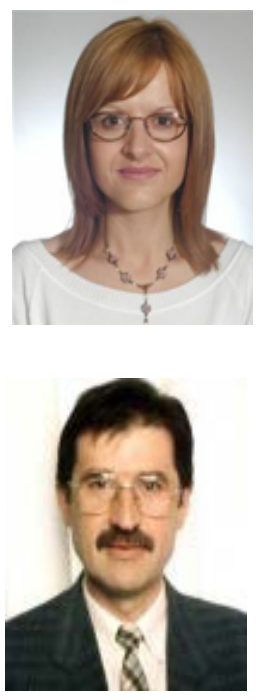

Vesna S. Ružičić was born in Trstenik, Serbia, in 1975. She received BSc, MSc and PhD degrees in Technics and Informatics in 1998, 2006 and 2018 respectively at Faculty of Technical Sciences Čačak, University of Kragujevac, Serbia. Her field of specialization is Information systems. She is the author of over 40 papers. Since 2000 she has been working at the Faculty of Technical Sciences in Čačak. Currently, she works as a assistant professor at the University of Kragujevac, Faculty of technical sciences in Čačak, Department of Information Technology.

Živadin M. Micić was born in Serbia, in 1955. His research interests include computer science, information technology, information and communication technologies, operating systems, expert systems, Web application development, methodology of science and IT in education. He is the author of over 230 papers, "Information Technology" monograph, "IT in integrated systems," etc., especially teaching publications for online usage. Currently, he works as a full professor at the University of Kragujevac, Faculty of technical sciences in Čačak, Department of Information Technology. 